
Address: Sector 11, Jankipuram Vistar, Lucknow, Uttar Pradesh, India

\title{
GOVERNMENT'S EFFORT IN CONTROL ENGINEERING EDUCATION IN INDIA
}

\begin{abstract}
Present manuscript deals with the Indian government effort in making the control engineering education, an equal standard to any developed country. Control Engineering is an interdisciplinary field of engineering which has an ample number of applications in the almost every core engineering discipline. This is the field which uses the feedback system to get the appropriate performance of the system without any human interaction. Mathematical modelling for the system designs is now performed on the simulation tools. There are multiple steps taken for control-engineering education by the Indian Government, which is a modern technology, applied in daily use from instruments to spacecraft. This manuscript gives a complete overview of different effort taken by the Indian Government to enhance the control engineering education such as developing online courses, online virtual labs, Scilab software packages, Scilab codes for books \& Scilab cloud. NPTEL video courses, which are available on online platform, help the students as well as other academicians who have deep interest in the topics related to the control engineering. Virtual labs give the students power to perform the experiment online without setup of any specialized labs through the internet enable device. Scilab cloud is an open source software platform which gives a platform to the students to design the code for the problem \& analysis it by changing the associated parameters with it. Textbook companion project is the associated project with scilab cloud in which scilab codes are developed for the solved examples of the certain engineering books. Doctoral thesis from the Indian institutes can be access through online at shodhaganga. With the implementation of $4 G$ telecommunication technology in India, NPTEL videos, Scilab cloud \& virtual lab can be accessed through the smartphone without computers or installing the software in smartphone.

Keywords: Engineering Education, India, Scilab, Control Engineering Education, Employment, Technical Education System, Interdisciplinary.

\section{INTRODUCTION}

Control systems engineering or instrumentation \& control engineering is the engineering discipline that applies concepts of control theory to design systems with desired output. The practice uses the different type of sensors to measure the output response of the system being controlled and those measurements are given as feedback to the input actuators that can make appropriate changes toward desired output response.
\end{abstract}


Control Engineering is the interdisciplinary branch, which has a close relationship with electrical engineering, electronics engineering, mechanical engineering, automobile engineering, instrumentation engineering, mechatronics engineering, aerospace engineering \& chemical engineering (Bajpai, \& Khare, 2015). Applications of control engineering have been found in our daily life product such as washing machine, microwave oven, automobile products etc. (Subbarao, 2013). Engineering Education plays a great role in creating skill manpower, improving the productivity of production units \& increasing the quality of life of any nation. Engineering also has the big contribution in any country economy. The Indian government has taken the many steps to improve the quality of engineering education across the nation with the help of different ICT (Information and Communications Technologies) (Bhattacharya, 2008; Subramanian, 2015).

In terms of control engineering, control engineering is offer as an independent engineering discipline in many technical institutes across India, in the name of "Instrumentation \& Control". It also offers as one-semester mandatory course named as Automatic Control System for Electronics \& Communication, Electrical Engineering, Mechanical Engineering Mechatronics Engineering \& other engineering disciplines at the undergraduate level. Postgraduate level, control engineering is offer as specialization (major) Process Control and Instrumentation engineering, Systems \& Control, Control \& Automation, Control \& Computing, Control \& Industrial Automation, Control System engineering, Instrumentation \& Control, Power and Control and Power System \& Control, by Electrical Engineering Department or Electronics \& Communication Engineering Department in India. Doctoral \& post-doctoral research on control engineering is conducted in premium technical institutions in India (All India, 2016; Mohanty, \& Dash, 2016).

\section{THE AIM OF THE STUDY}

India is a big country with seventh in rank by area \& second in rank by population in the world. India was a hub of science \& technology in ancient time. The aim is to give an overview of the Indian government efforts in the field of control engineering. Control engineering is the field, which connects the multiple engineering disciplines (instrumentation \& control engineering, electronics \& communication engineering, electrical engineering, mechanical engineering, mechatronics engineering, automobile engineering etc.). Due to Make of India, an initiative initiated by the Government of India, multiple industries are (will be) setting their industrial units in India. Sectors like automobile (including electric), aviation, defense manufacturing \& renewable energy where this CE plays a great role in the development of the product. For product development, companies need the smart engineer. To fulfill the demand smart \& creative engineers, technical institutes need to use the modern technology to teach the inside of control engineering (Agarwal, 2007; Dixit, Hazarika, \& Davim, 2017).

\section{THEORETICAL FRAMEWORK AND RESERCH METHODS}

Theoretical framework of present research consists of current data on Indian government effects in specific to the Control Engineering field. Indian government is now taking the multiple steps to improve the quality of the engineering education across India through the dedicated department of Ministry of Human Resource Development. Web based learning, use of open source tools in labs, online workshops, online doctoral thesis database are major initiatives which are used to enhance the engineering education in India.

Data had been collected through the NPTEL website course regarding the Control Engineering and the statistical representation has been given in the paper for NPTEL courses which is given by the renowned faculties in India related to the Control Engineering. Virtual lab details have been gathered from the virtual lab website which is 
under the specialization of Mechanical or Electrical or Electronics Engineering. Scilab cloud, which is an online simulation tool, is used for the analysis of the mathematical equation associated with the control engineering. This online platform can be driven from the $4 \mathrm{G}$ enable smartphone to draw the different plots or solving the mathematical equations. Shodhaganga \& Shodagangotri is an online platform for collection of the research data (thesis) associated to the doctoral research in India.

\section{RESULTS}

The analysis of the contribution has been done through the different sub segments which capture the effort of the Indian Government specific to the control engineering. Due to the interdisciplinary field of engineering, some common efforts related to the engineering have been also capture in this manuscript.

\section{Web Base Learning Through Video Lectures}

MHRD has developed an online database (National Programme on Technology Enhanced Learning) of the video lectures of renowned faculties across India. Initially, it was started in 2003 with Indian Institute of Science with seven old Indian Institute of Technology. Indian Institute of Technology, Madras (Chennai) is the main coordinating institute for NPTEL program. There are twenty-six video \& web based lectures dedicated to Control Engineering which include basic control engineering, aeroscopic control, digital control, process control, computational control, industrial automation, non-linear control, stability and control, optimal control \& instrumentation and process control (Ananth, 2011).

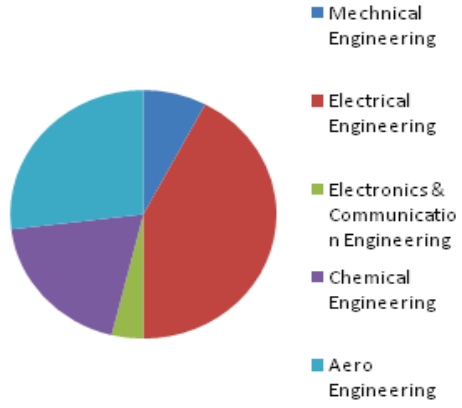

Fig. 1. Contribution by the different departments in NTPEL courses of control engineering NPTEL Video Courses

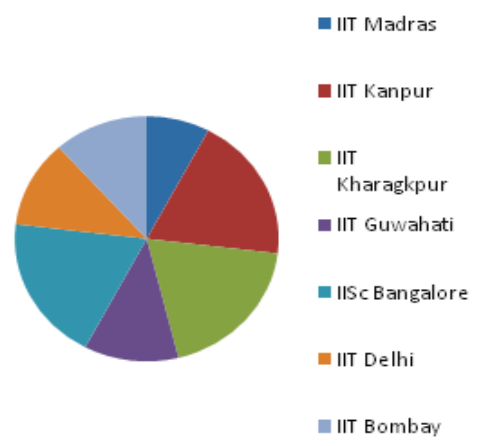

Fig. 2. Contribution by the different institutes in control engineering NPTEL courses 
Figure 1 represents statics of the contribution by the department in designing the course \& Figure 2 represents statics of the contribution by the institutes in designing the NPTEL course.

These courses are specialized courses, which are useful for the undergraduate and postgraduate students as well as doctoral students who are working in the area of control engineering. Basic control engineering course (three) is also useful for the students (electrical \& electronics engineering) who are preparing for different competitive examinations (Krishnan, 2009).

\section{SHODHAGANGA}

Shodhaganga is the online digital repository of a doctoral thesis (electronics version). Since thesis is known as to be rich of information in the specific topic or field. It is an Indian intellectual output, stored in a repository hosted and maintained by the INFLIBNET Centre at Gandhinagar, Gujrat. This help students to get the data \& information online, without moving from one institution to another institution to fetch the information \& also prevent the duplicate in the ongoing research. Many institutions in India join this library network (Sivakumaren, 2015).

A new type of database is now developed named as Shodha Gangotri, which maintains the initial research synopsis of the researcher. This online database also helps the candidates to prevent the duplicate research work. After the student submits the doctoral thesis at Shidhaganga, his or her synopsis will be mapped with the submitted thesis at shodhagangotri.

\section{OPEN SOURCE TOOLS}

MHRD in India has started Free and Open Software in Education (FOSSEE) project to promotes the use of open source tools instead of proprietary software at different technical institutes throughout the country. Indian Institute of Technology, Bombay is the monitoring institute for this project. Through this project, MHRD is now developing its own open source software tools and software packages for Scilab. There is package developed for control engineering in Scilab but an independent tool for control engineering has not been developed yet. Mathematical modeling problems (simulation) are solved with the help of Scilab or GNU Octave. Block level model problems are solved with the help of Scicos \& Xcos which is an open source tool similar to Simulink. Mathematical optimization problems are solved with the help of OR tool which is developed by the FOSSEE India.

A low kit related to Programmable Logic Controllers (PLC) is in developing phase which is going to replace the costly PLC kits, which is useful for the undergraduate students.

\section{TEXTBOOK COMPANION (TBC) PROJECT}

TBC project has given an opportunity to the students \& researchers to develop the code of Scilab of solved examples from the standard textbooks. A student who worked under this, gets paid for the work. After reviewing process, Scilab codes uploaded to the Scilab India website for free download (Bajpai, Asif \& Akhtar, 2016). Through this codes, students can change the value of the different variables in the problem and do the comparative analysis of the outcome. This will save the time of mathematical calculations in multiple folds \& student can think over the problems from different ways. There have been developed twelve books on the control engineering and one book is in under development phase. Students who work under this project to develop the codes of the solved examples are eligible to get some amount for that work after it got completed. 


\section{DEVELOPMENT OF SCILAB CLOUD}

A cloud service named as "GARUDA" has been developed to execute the codes of Scilab online without installing Scilab software in the computer. This cloud has been developed by the FOSSEE team \& CDAC, Bangalore. Only high-speed internet connection is needed for the execution of the code which is written by the student on the screen and put the Execute tab (Khare, Chatterjee, Bajpai \& Bharati, 2016). Online codes of the books are available whose code are developed under the project Textbook Companion Project. Total eleven books have been completed under this project for control engineering. These codes (parameters in the problem) can be changed \& students can see the respective changes in the outcome through this. This

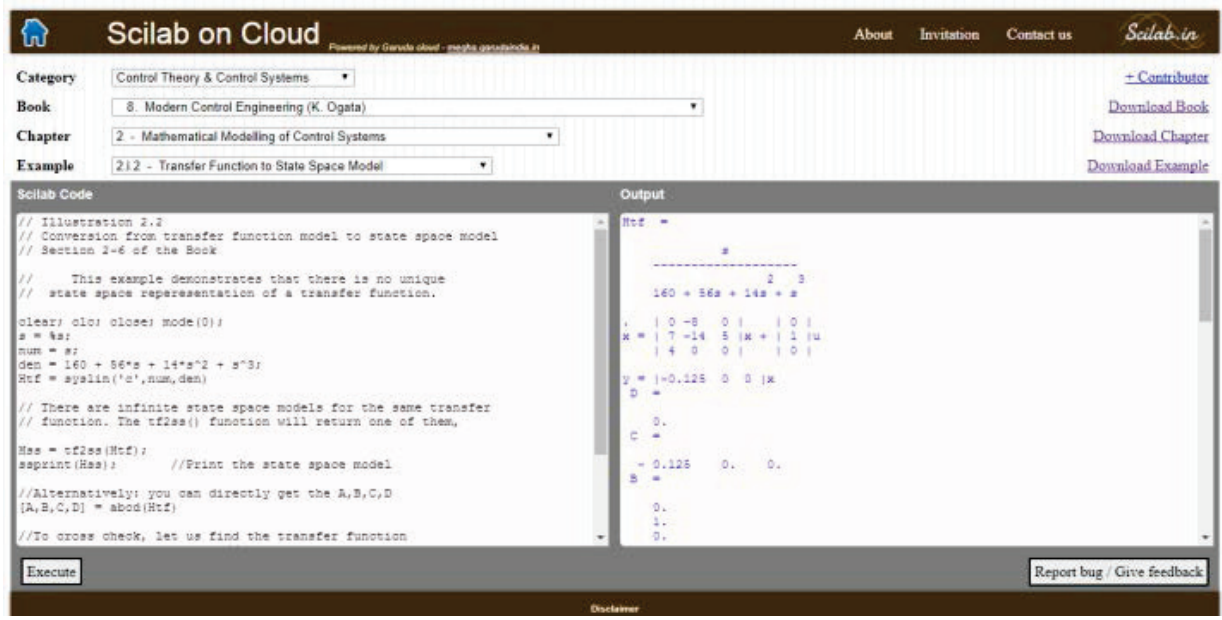

Fig. 3. Execution of the Scilab code of transfer function to state space model (based on Modern Control Engineering by K. Ogata)

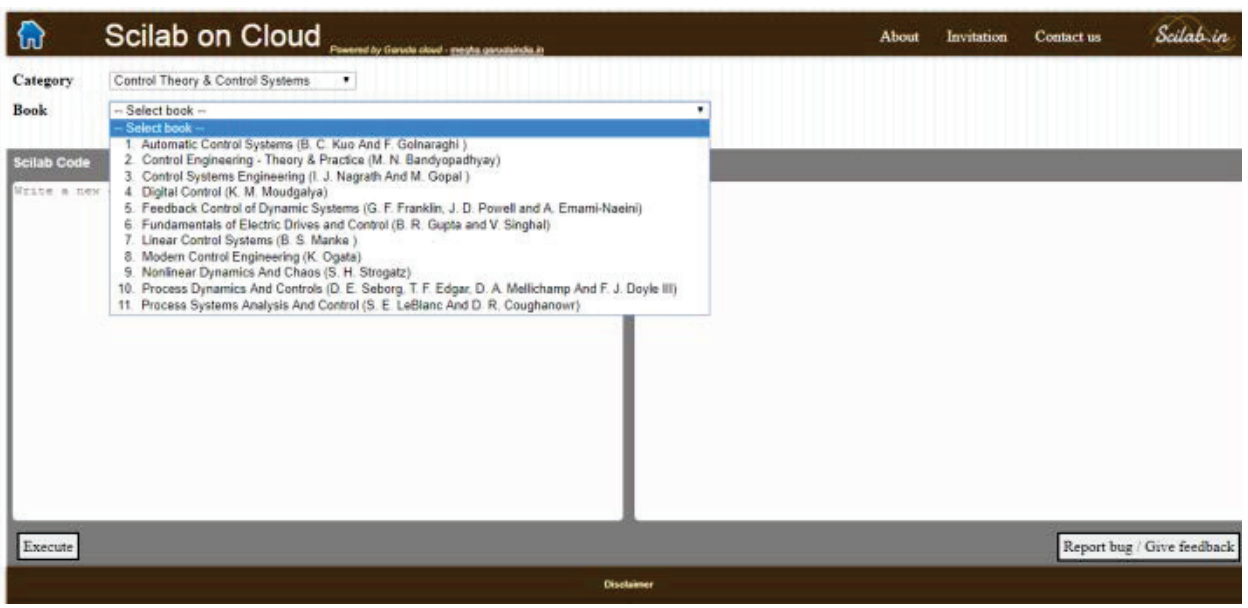

Fig. 4. Books having Scilab code available under the cloud GARUDA 
Online facility has been ported by the FOSSEE team to the GARUDA Grid with the help from the GARUDA Team at CDAC, Bangalore (Shrish, Sushant \& Rishab, 2016). Figure 5 and Figure 6 show comparative analysis of Bode plot of a transfer function that has different natural frequencies. Changing the parameters in the problems helps a student to understand the concept of the different topics. It also reduces the mathematical calculation part of the student as well as save the time of the students.

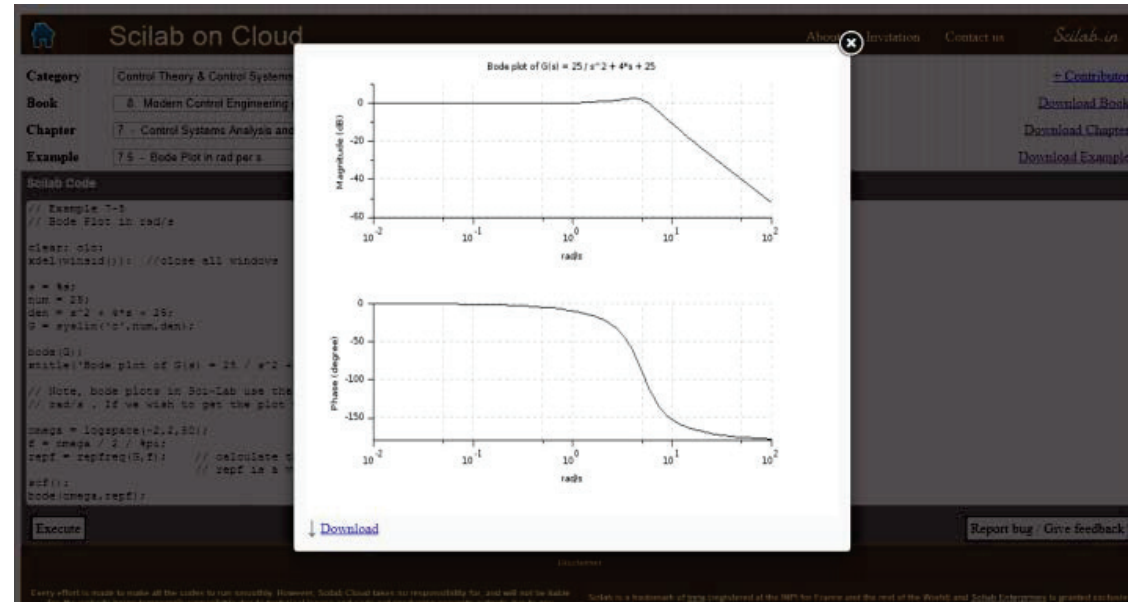

Fig. 5. Designing of Bode plot using Scilab at Garuda cloud

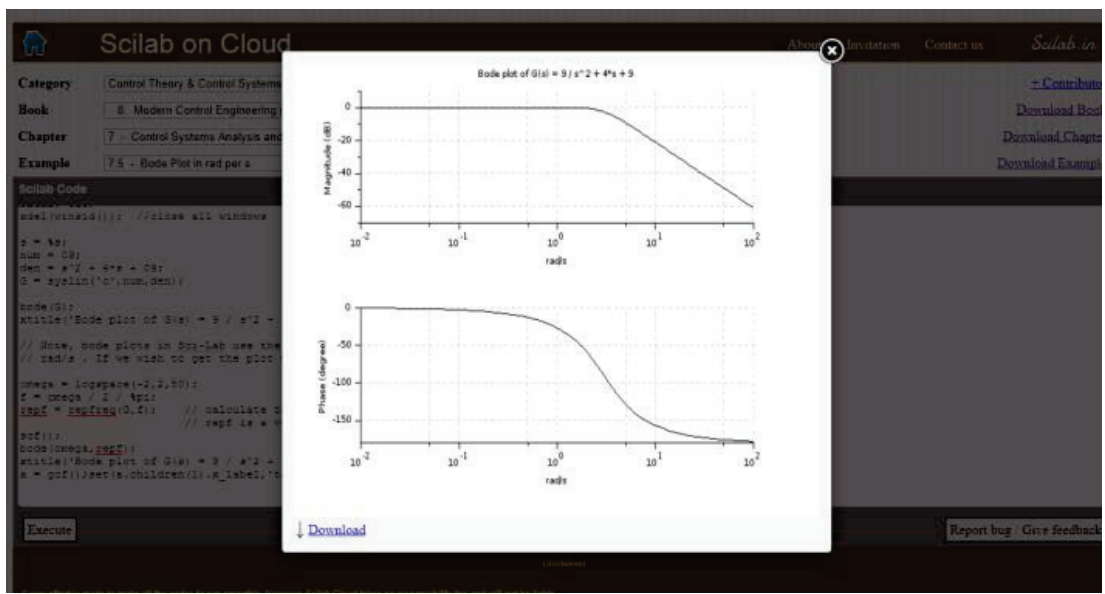

Fig. 6. Designing of Bode plot using Scilab at Garuda cloud

\section{LAB MIGRATION PROJECT}

Lab Migration project aims to migrate labs from Proprietary software to open source software. Proprietary software such as Matlab, Simulink, LabVIEW is used in different topics associated to control system. The Indian government is sponsoring the lab 
migration project (Bajpai \& Akhtar, 2017). Through this project, till September 2016 ten labs (total fifty-three) of the control system have been converted \& one lab (total fourteen) is under development phase and these labs are using Scilab \& Xcos. These labs have online code Scilab codes (downloadable).

Experiments related to transfer function generation, block diagram reduction technique, signal flow diagram, feedback characteristics, stability analysis (bode plot, root locus, nyquist plot \& polar plot) linear system analysis, state space model, checking controllability \& observability of a system simulation of P, PI PD \& PID controller etc. are the major experiments whose Scilab codes are available online for this project which can be accessed without any cost. These lab codes are helpful to the students as they can execute on their own system and can be also executed through Garuda cloud without any authentication.

\section{SPOKEN TUTORIAL}

The spoken tutorial project is designed to improve the learning about teaching and learning of a particular open source software or tools. This is a screencast with running audio \& recorded computer session specially created for self-learning. Each video runs up to ten minutes. Through this, any student can learn open source tools such as Scilab, Scicos, Latex etc. which is necessary to work with the control engineering field (Sohoni, 2016).

\section{VIRTUAL LAB}

Virtual lab project has been developed by the MHRD under the National Mission on Education through ICT. Its main aim is to provide remote access to labs in different engineering branches (Sánchez, Zamora, \& García, 2016). Each lab provides a complete for learning management system in which students can use various tools for learning the concept. Through this project, costly instruments are shared across the different geographical locations.

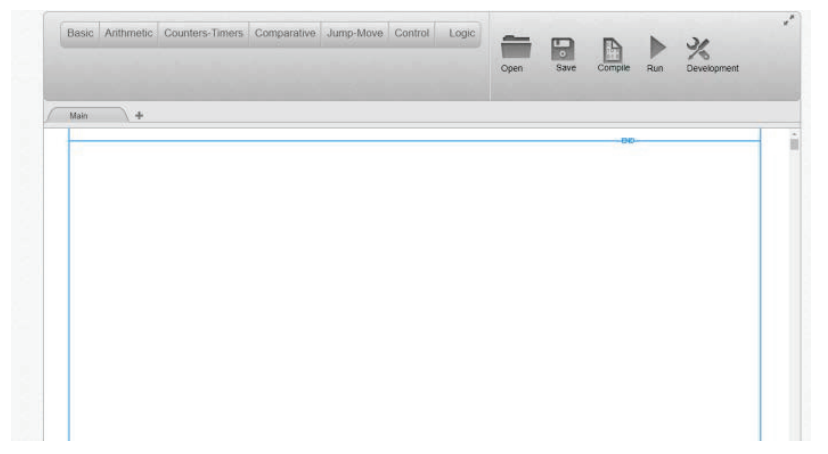

Fig. 7. Virtual lab related to PLC instruments

There are two labs developed for Control Engineering. Systems, Communication \& Control Laboratory has been developed by Indian Institute of Technology (I.I.T.), Guwahati which includes some experiments correlated to control system engineering. Another lab is PLC lab which having the experiments on different controller, is developed by College of Engineering (CoEP), Pune, which includes the test on different systems. Fig. 7 shows the front screen of the PLC lab experiment.

\section{AAKASH}

A low-cost android \& GNU/Linux version based computer tablet \& laptop has been developed by MHRD name as Aakash (previously Sakshat), to support e-learning 
project throughout India. This tablet is being manufactured in India (now) at Hyderabad. Scilab (Version 5.4) is supported on android Aakash tablet. Scilab (Version 5.3) is supported on updated Ubuntu 12.10 version of Aakash laptop which is made by the Datawind (Canadian company). All features of laptop installed in Scilab are not available in the tablet with installed Scilab, but the basic functionality of computation code and generation different plots are easily done in the Aakash tablet. This project has been developing to delivered as one child one laptop.

\section{WORKSHOPS}

MHRD is conducting workshops on open source software \& software packages through contact workshop, remote workshop (Through the internet) \& self-workshop. There are multiple workshops for the Scilab \& Xcos which are used to solve the mathematical \& simulation problems related to control engineering (Mohapatra \& Mohanty, 2017).

Beside this, MOOCs (Massive Open Online Course) are widely used in distance education which was first introduced in 2008. Many faculties in India have developed their own MOOC (Massive Open Online Course) classes which are aimed at participation of students in virtual classroom having limited functionality (distribution or accessed or share) of lecture notes, problem sets, quizzes, presentations etc.

\section{CONCLUSIONS}

There are many steps Indian government has taken to improve and enhance the engineering education. The Indian government has also taken multiple initiatives for the improve job opportunities for engineers having a background related to control engineering. The Indian government has taken the steps to establish the core industries (which relates to the control engineering) such as defence, aeronautics \& machinery in major. Still, India imports as much as more than seventy-five percent of products related to above sectors. Establishment of such industries will boost the job opportunities for engineers having control engineering background. Moreover, these steps also boost the job opportunities for other sectors.

Research sector is also got the boost due to the change in the government policies. Now faculties of research institutes \& academic institutes are getting research project easily. Last few years, ISRO is aggressively moving towards to increase it is market share in space market. ISRO has the highest percentage of successful space missions. Control engineering is an integral part of space science. Each spacecraft has multiple controlling devices.

Control Engineering is one of the top fields of engineering in which MHRD is working to develop the associated material. But, more should be done in this field. India lacks a dedicated institute on control engineering in which almost all types of related courses are offered $\&$ researches on different subfields of control engineering can be done. No Indian Institute of technology has dedicated department for that and only in two National Institute of Technology has dedicated department on control engineering. MHRD has to open some research faculties in the newly established IITs or NITs on control engineering and one or more institute as a research-driven institute for control engineering. There is a lack of the collaboration on the research project(s) in between any two indian technical institutes. FOSSEE India is annually organizing a conference named SciPy India from 2009 to give a platform to the researcher, students \& academician to present their work in the conference in broad level.

These initiatives also helps the undergraduate, postgraduate and doctoral students in grow in knowledge as well as skill. Online labs not only help the students but also give a opportunities to work with the instruments which are not available in their campus. Scilab a open source simulation tool can work in solving the mathematical problem through 
computer program. Some tool boxes associated to the Scilab had been developed and some are in developing stages. Development ot toolboxes is done by the Indian students which also get the financial assistance ships by Indian Government. Shodhaganga is the online library of the collection of the doctoral research thesis, work done by the Indian doctoral researchers in the different fields.

\section{REFERENCES}

1. Agarwal, P. (2007). Higher education in India: Growth, concerns and change agenda. Higher Education Quarterly, 61 (2), 197-207.

2. All India Council for Technical Education Approval Process Handbook 2017 2018) . (2016). Retrieved from https://www.aicteindia.org/downloads/Final\%20_Approval\%20Process\%20Handbook\%202017-18.pdf.

3. Ananth, M. (2011). National programme on technology enhanced learning (NPTEL): The vision and the mission. Technology for Education (T4E), 2011, 8.

4. Bajpai, S., Khare, S., \& Yadav, R. (2016). Control education in India: present \& future. IFAC-PapersOnLine, 49 (1), 813-818.

5. Bajpai, S., \& Khare, S. (2015). Mechatronics engineering education in India. Comparative professional pedagogy, 5 (4), 73-79.

6. Bajpai, S., \& Akhtar, S. (2017). Industrial engineering education in India. Comparative professional pedagogy, 7 (3), 84-92.

7. Bajpai, S., Asif, S. S., \& Akhtar, S. A. (2016). Electromagnetic education in India. Comparative professional pedagogy, 6 (2), 60-66.

8. Bhattacharya, B. (2008). Engineering education in India - the role of ICT. Innovations in education and teaching international, 45 (2), 93-101.

9. Dixit, U. S., Hazarika, M., \& Davim, J. P. (2017). A brief history of mechanical engineering. India

10. Khare, S., Bajpai, S., \& Bharati, P. K. (2015). Production engineering education in India. Management and production engineering review, 6 (1), 21-25.

11. Khare, S., Chatterjee, A., Bajpai, S., \& Bharati, P. K. (2016). Manufacturing engineering education in India. Management and production engineering review, 7 (1), 40-44.

12. Krishnan, M. S. (2009, August). NPTEL: A programme for free online and open engineering and science education. In Technology for Education, 2009. T4E'09. International Workshop on (pp. 1-5). IEEE.

13. Mohapatra, S., \& Mohanty, R. (2017). Adopting MOOCs for afforable quality education. Education and information technologies, 22 (5), 2027-2053.

14. Mohanty, A., \& Dash, D. (2016). Engineering education in India: preparation of professional engineering educators. Journal of human resource and sustainability studies, 4 (2), 92-101.

15. Sánchez, J. V. V., Zamora, J. A. M., \& García, F. J. Á. (2016). Virtual lab for digital systems. In Technologies Applied to Electronics Teaching (TAEE), 2016 (pp. 1-7). IEEE.

16. Sivakumaren, K. S. (2015). Electronic thesis and dissertations (ETDs) by Indian universities in Shodhganga project: a study. Journal of advances in library and information science, 4 (1), 62-66.

17. Sohoni, M. (2016). The AICTE review: an opportunity for engineering education reform. Current science, 110 (2), 159-166.

18. Subbarao, E. C. (2013). India's higher engineering education: opportunities and tough choices. Current Science, 104 (1), 55-66.

19. Subramanian, B. (2015). Engineering Education in India: A Comprehensive Overview. In International Perspectives on Engineering Education (pp. 105-123). Springer, Cham. 